levels on the same varicosity, has not resulted in thrombosis of the tributary, presumably owing to deep entry and exit from the isolated segment. The answer is ligation by which, through a small transverse incision, the vein is pulled down proximally and distally so that $3-4$ in $(7 \cdot 5-10 \mathrm{~cm})$ of the varicose vein can be removed in stepwise fashion. This is, of course, timeconsuming, especially if one takes the trouble to close the wounds in a cosmetic manner with a subcuticular suture.

The practical compromise, therefore, would be to reserve sclerosant treatment for varicosities below the knee with no suggestion of saphenofemoral inoompetence; surgery is indicated if this incompetence is suspected, for varicosities above the knee, and for those below the knee if time permits. I find many patients grateful for the fact that all the veins are dealt with simultaneously and they do not have to wear irksome bandages for six weeks.-I am, etc.,

The Infirmary,

I. G. SChraibmaN

1 Hobbs, J. T, in The Treatment of Varicose Veins by Injection and Compression. Proceedings of the Stoke Mandeville Symbosium,
Hereford, Pharmaceuticals Research, 1971 .

\section{Ischaemic Heart Disease and Pernicious} Anaemia

SIR,-For 15 years I have been observing a group of 300 men in a mixed industrial and rural general practice with special reference to ischaemic heart disease (I.H.D.), work which was assisted in the beginning by a B.M.A. research grant.

The factors which are commonly considered-namely, diet, serum lipids, obesity, hypertension, exercise, stress, and smoking -have been difficult to correlate with the observed incidence of I.H.D., but I have been impressed by the virtual absence of I.H.D. in other patients in the practice who require regular maintenance therapy for Addisonian pernicious anaemia (P.A.). I have been unable to find reference to this in published papers or textbooks. One such patient does, in fact, have angina of effort, but this preceded the development of P.A. by several years, and in the eight years that he has had regular treatment for the P.A. his condition has not deteriorated and in this long time he has not had a myocardial infarction. It seems relevant, too, that the men in my practice who have P.A. have low serum cholesterol levels. However, the in cidence of P.A. is about three per 1000 and I never have more than 18 cases at one time. The validity of these observations would therefore need to be tested by a number of doctors.

If confirmed, this pases three questions. Is I.H.D. preceded by low serum vitamin $\mathbf{B}_{12}$ levels? Does cyanocobalamin proteot the vasculature? Or does gastric achlorhydria interfere with lipid metabolism in a way which retards or prevents the development of atherosclerosis? Further investigation might be worth while and I write in the hope that someone may be interested because, after 43 years in general practice, I do not feel inclined to start something which I may not have the opportunity of finishing. -I am, etc.,

Kidsgrove, Staffs

\section{Working of the Abortion Act}

SIR,-After four years away from the British in the working of the Abortion Act 1967. Doctors, and particularly general practitioners, are listening to the requests of women for abortion much more readily and sympathetically. The N.H.S. has carried out an increasing number of abortions and pregnancy is being terminated earlier and by safer techniques. However, now is not the time for complacency; much remains to be done. The N.H.S. should be doing a greater proportion of the total abortions performed. The referral process should be accelerated. Pregnancy should be terminated as early as possible in pregnancy and by the safest techniques (vacuum aspiration under local anaesthesia or premedication). No only would women be spared much unnecessary emotional and physical trauma but these measures also would enable the N.H.S. to accept the load without the need for the costly admission of women to hospital. Doctors other than gynaecologists could acquire the necessary skills to terminate pregnancies of less than 10 weeks duration on an outpatient basis.

As I recall, doctors were quite vocal in expressing opposition to the Abortion Act during its passage through Parliament. I wonder whether others would agree with me that there has been a curious and uncanny silence on the part of the majority of the medical profession in response to the second reading of the Abortion (Amendment) Bill. This is also a subject that does not call for complacency. The Abortion Aot can and will be destroyed by those with minority views who are opposing it very vigorously unless active steps are taken to preserve it. Doctors must take part in the public debate concerning abortion, and most especially if they also defend the right of women to control their own fertility.-I am, etc.,

Peter J. Huntingford

Department of Obstetrics and Gynaecology,

The London Hospital Medical College, London E.1

\section{Debrisoquine, Guanethidine, and} Bethanidine in Hypertension

SIR, - We were interested in the study by Dr. F. C. Adi and others (1 March, p. 482) of the effects of debrisoquine and guanethidine in hypertensive patients and felt that our slightly more extensive experience would be of interest.

From 1968 to 1972229 patients were allocated to a study of the relative hypotensive effects of debrisoquine, guanethidine, and bethanidine in severe hypertension (casual diastolic pressure $>120 \mathrm{~mm} \mathrm{Hg}$ ). The treatment for each patient was selected with the use of a code and the patients were followed up for at least two years, the dose of drug being adjusted as necessary for scene I can detect much that has changed

optimum control of hypertension without side effects.

The blood pressure levels before treatment were similar in each treatment group and the groups appeared comparable. The blood pressure levels afiter one year's treatment are shown in the table. The blood pressure levels were lower in the groups of patients treated with debrisoquine and guanethidine than in the group treated with bethanidine. The standing diastolic pressures of patients treated with debrisoquine and guanethidine were significantly lower than the same measurements in patients treated with bethanidine $(t=3 \cdot 1, P<0.01)$. Symptoms of orthostatic or exertional hypotension were significantly more frequent in patients treated with guanethidine $(25.6 \%)$ than in patients treated with bethanidine $(18.4 \%)$ or debrisoquine $(17.6 \%) \quad(P<0.01)$. Other symptoms, particularly diarshoea, were also more frequent and troublesome in patients on guanethidine; $23 \%$ of patients on guanethidine, $4 \%$ on bethanidine, and $1 \%$ on debrisoquine complained of diarrhoea.

Subsequent follow up has been possible for only 41 patients on guanethidine, 42 on debrisoquine, and 28 on bethanidine. The majority of patients were removed from the study in order to improve control of hypertension without side effects and this necessitated giving additional drugs such as $\alpha$-methyldopa or beta-blockers. The greater proportion of patients on bethanidine needing additional therapy supports our view that hypertension is not as well controlled by this drug as by the other two. We would agree that debrisoquine is as effective a hypotensive drug as guanethidine and less liable to produce hypotensive symptoms. -We are, etc.,

S. TALbot

B. C. O'MALLEY

R. F. BING

Sheffield Hypertension Clinic, Sheffield Royal Infirmary

\section{Availabilty of Glyceryl Trinitrate}

SIR,-In common, no doubt, with many of my colleagues in general practice I have tended to assess the severity of patients' angina (and their response to treatment-for example, with beta-blockers) by the frequency with which repeat prescriptions for glyceryl trinitrate are requested-until last week, that is, when a patient declined a repeat prescription and informed me that he had been buying trinitrin over the counter at $10 p$ for 100 . (I subsequently verified this by purchasing several bottles of glyceryl trinitrate in various branches of a large retail chain of chemists.)

I find this surprising, to say the least, and feel that this must raise a number of questions-particularly in view of the discussions on the availability of "over the counter" drugs.-I am, etc.,

S. V. STEINBERG

Glasgow

Blood Pressure Levels (Mean \pm S.D.) after One Year's Treatment

\begin{tabular}{|c|c|c|c|}
\hline & Guanethidine & Debrisoquine & Bethanidine \\
\hline $\begin{array}{l}\text { Systolic pressure lying }(\mathrm{mm} \mathrm{Hg}) \\
\text { Systolic pressure standing }(\mathrm{mm} \mathrm{Hg}) \\
\text { Diastolic pressure lying }(\mathrm{mm} \mathrm{Hg}) \\
\text { Diastolic pressure standing }(\mathrm{mm} \mathrm{Hg}) \\
\text { Noo of patients } \\
\text { No. also taking diuretic }\end{array}$ & $\begin{aligned} & 169 \cdot 3 \pm 29 \cdot 2 \\
& 161 \cdot 9 \pm 29 \cdot 5 \\
& 98 \cdot 1 \pm 19 \cdot 5 \\
& 94 \cdot 6 \pm 15 \cdot 0 \\
& 78 \\
& 53\end{aligned}$ & $\begin{array}{c}166 \cdot 4 \pm 28 \cdot 4 \\
154 \cdot 9 \pm 28 \cdot 6 \\
98 \cdot 0 \pm 17 \cdot 1 \\
94 \cdot 1 \pm 16 \cdot 7 \\
78 \\
35\end{array}$ & $\begin{array}{l}170 \cdot 6 \pm 30 \cdot 9 \\
165 \cdot 0 \pm 30 \cdot 8 \\
103 \cdot 8 \pm 13 \cdot 6 \\
100 \cdot 8 \pm 11 \cdot 9 \\
73 \\
35\end{array}$ \\
\hline
\end{tabular}

